\title{
A Alfabetização Científica Inerente à Formação de Professores: o que dizem as pesquisas quanto às perspectivas para o Ensino de Ciências
}

\author{
Teresa Beatriz Bueno*, Luciana Sedano*
}

\section{Resumo}

Diversas pesquisas têm investigado o ensino e a aprendizagem das ciências com enfoque na Alfabetização Científica (AC), visando uma formação de cidadãos que vá além das aprendizagens conceituais. Porém, poucas delas investigam a formação dos professores para a atuação nas salas de aula quanto à sua aproximação com os processos de AC. Sendo assim, o objetivo do presente texto foi analisar o perfil dos estudos, com enfoque para a formação de professores, sobre as estratégias de ensino utilizadas para promover a AC e como essas abordagens de ensino têm se aproximado de discussões sobre a prática científica. Para isso, realizou-se uma pesquisa bibliográfica nas principais revistas da área de Ensino de Ciências e nos anais do Encontro Nacional de Pesquisas em Educação em Ciências (ENPEC) do período de 2014 a 2019. As categorias de análise foram: sentidos/significados atribuídos pelos professores à AC; abordagens e estratégias utilizadas nos processos formativos com foco na AC; reflexão e delineamento acerca da prática pedagógica objetivando a AC. Identificamos poucos trabalhos no contexto formativo, inicial e continuado, dos professores. Os resultados destacam que ainda há pouco aprofundamento quanto às discussões dos aspectos que contemplam os objetivos da AC. A ideia de refletir sobre suas características é incentivada nos trabalhos, contudo a reflexão pauta-se ainda em uma ideia mais generalizada, sem que se discuta com afinco a mudança para a prática dos professores. Ainda assim, alguns trabalhos destacam as atividades investigativas como principal meio de promover a $\mathrm{AC}$, uma vez que direcionam os professores à criticidade e reflexões, entre outras habilidades necessárias para uma pessoa ser alfabetizada cientificamente. Ressaltamos então a importância de incorporar na formação de professores ações que viabilizem uma mudança de atitudes quanto à sua prática em sala de aula na educação básica.

Palavras-Chave: Alfabetização Científica. Ensino de Ciências. Formação de Professores. Formação inicial e Continuada.

\footnotetext{
Licenciada em Ciências Biológicas pela Universidade Federal do Piauí (UFPI). Pós-Graduanda em Educação em Ciências e Matemática (PPGECM) pela Universidade Estadual de Santa Cruz (UESC), Ilhéus, Bahia. E-mail: teresab.bueno@gmail.com

* Doutora em Educação pela Universidade de São Paulo (USP). Professora do Departamento de Ciências da Educação (DCIE). Docente do Programa de Mestrado Profissional em Educação (PPGE) e do Programa de Mestrado Acadêmico em Educação em Ciências e Matemática (PPGECM) da Universidade Estadual de Santa Cruz (UESC), Ilhéus, Bahia. E-mail: luciana.sedano@gmail.com
} 


\section{Introdução}

Segundo Chassot (2003), é necessário, além de ensinar conhecimento, ensinar como usá-lo, tornando-o um facilitador de uma leitura de mundo mais adequada e, principalmente, mais crítica, ou seja, devemos ensinar Ciências com uma linguagem que facilite $o$ entendimento do mundo pelos estudantes. $\mathrm{O}$ autor discute a necessidade de alfabetizar cientificamente os sujeitos e chama atenção para o fato de que a Alfabetização Científica (AC) não seja de interesse apenas daqueles que estão diretamente ligados à Ciência (CHASSOT, 2018). Referente a isso, autores na área têm se preocupado em investigar o ensino e a aprendizagem das ciências sob o enfoque da $\mathrm{AC}$, visando oportunizar aos estudantes aprendizados que vão além de conceitos, possibilitando-os conhecer e reconhecer as ciências como área de conhecimento da humanidade imersa nos contextos social, cultural e histórico (SASSERON; DUSCHL, 2016).

Um dos desafios do ensino escolar dos últimos anos refere-se a um Ensino de Ciências que contribua para a promoção da AC em todos os níveis de ensino que constituem a educação escolar, uma vez que ela amplia e enriquece a visão de mundo dos cidadãos e permite que os estudantes se aproximem dos conhecimentos científicos e construam conceitos a partir deles, problematizando questões em torno da ciência (CACHAPUZ; GIL-PEREZ; PESSOA, 2011). É nesse sentido que alguns autores investigam de que modo a AC ocorre e como é possível um ensino visando a criticidade dos estudantes por meio de estratégias que promovam a AC, como Sasseron (2008) que sugere indicadores da AC em que é possível observar nos estudantes quando estes são colocados diante de atividades com competências próprias do fazer científico.

Atualmente, diversas pesquisas em EC têm defendido a importância de incorporar à prática docente propostas que visem o caráter exploratório por meio de abordagens investigativas e problematizadoras, objetivando a formação do cidadão crítico, sendo este um dos maiores desafios para a escola atualmente (BRITO; FIREMAN, 2016; CARVALHO, 2013; SASSERON; CARVALHO, 2011; CHASSOT, 2010; SEDANO; CARVALHO, 2017).

Sasseron (2015) define que a AC tem sido um dos principais objetivos do Ensino de Ciências, pois a partir do contato que o aluno possui com saberes específicos da área, terá autonomia na tomada de decisões no âmbito social e político, embasado 
pelo conhecimento científico, e uma relação com o significado da ciência e tecnologia de uma forma geral, à medida que utiliza os conhecimentos da ciência em seu cotidiano. Para tanto, é imprescindível que a postura do professor seja essencial para mediar explicações científicas de maneira que os estudantes consigam refletir sobre elas e sejam capazes de elaborar soluções para as problematizações em sala de aula (SASSERON; CARVALHO, 2011).

Devido às diversas transformações pelas quais a sociedade tem passado, Suart e Marcondes (2018) reconhecem a importância de uma pessoa ser alfabetizada cientificamente para que possa entender desde as potencialidades até as implicações e agravos que a Ciência pode gerar, sabendo que a população deve exercer participação ativa sobre as decisões e tudo que envolva as discussões relacionadas aos diversos problemas que permeiam a sociedade. Para alcançar tal objetivo, é necessário que o Ensino de Ciências seja planejado de maneira que os estudantes sejam participantes dos processos de construção próprios dos conhecimentos científicos, bem como das relações da natureza das ciências, tendo posicionamento crítico e reflexivo em suas decisões individuais e grupais.

Andrade e Abílio (2018) acreditam que a AC nas escolas parte da iniciativa docente, e que a prática desses professores é orientada por ideias, concepções e teorias. Ao investigar as concepções de professores de Biologia sobre AC, buscando uma aproximação dos indícios dessa prática no espaço escolar, as autoras evidenciaram que os professores investigados não possuem um aprofundamento conceitual sobre a AC, reforçando assim necessidade de uma formação prática pedagógica mais crítica e reflexiva.

Seguindo algumas reflexões no contexto da formação de professores de Ciências, Carvalho e Gil-Pérez (2011) apontam para as necessidades formativas, indicando tendências e inovações nesse campo disciplinar. Os autores discutem que conhecimentos teóricos sobre aprendizagem, aprendizagem das Ciências, conhecimento pedagógico direcionado a avaliar o trabalho com os alunos configuram-se como algumas das necessidades indispensáveis para o perfil dos estudantes de licenciaturas e, caso sejam insuficientes, poderão futuramente reproduzir fundamentos e visões simplistas da Ciência no exercício da docência.

Diante disso, é indispensável que a formação docente se baseie também em processos de reflexão sobre suas próprias práticas, considerando a necessidade de a sociedade formar-se criticamente e atuar de modo consciente e reconhecendo as 
ciências como uma área de conhecimento diretamente ligada aos âmbitos sociais, políticos e culturais via articulação teórico-prática entre a Alfabetização Científica e a Formação Docente. Se pensarmos nos desafios relativos às mudanças pelas quais a educação necessita passar, importa considerar que os professores de ciências, em formação inicial ou continuada, compreendam que não é suficiente para ensinar o domínio dos conteúdos e teorias apenas. Isso nos leva a questionar: quais são os objetivos dos professores dentro das salas de aula? Como têm se aproximado dos processos de promoção da Alfabetização Científica?

Portanto, o objetivo desta investigação é analisar o perfil dos estudos, com enfoque para a formação de professores, sobre as estratégias de ensino utilizadas para promover a $\mathrm{AC}$ e como essas abordagens de ensino têm se aproximado de discussões sobre a prática científica. Esperamos que nossas reflexões contribuam para minimizar a lacuna existente nos trabalhos relativos à formação de professores na perspectiva da $\mathrm{AC}$, bem como cooperem para ampliar a formação científica dos educandos.

\section{Contribuições da Alfabetização Científica na formação dos cidadãos e aspectos para formação de professores}

O termo "scientific literacy" foi utilizado pela primeira vez pelo pesquisador Paul Hurd, uma das principais referências da área. O pesquisador discute a ideia de Alfabetização Científica com base nos principais acontecimentos históricos importantes para o Ensino de Ciências, conforme a necessidade de começar a ensinar Ciências nas escolas em todos os níveis de ensino, preparando os estudantes para saber mais sobre a ciência e suas implicações (SASSERON; CARVALHO, 2011).

Sasseron (2008) se refere ao termo AC no sentido de qualificar nossas ideias e objetivos ao planejar um ensino que leve os estudantes a imergirem em outra cultura, interagindo com novas formas de ver o mundo, podendo torná-los conscientes de saberes, noções e conhecimentos científicos, bem como das habilidades associadas ao fazer científico.

Ainda de acordo com a autora, a AC pode ser compreendida como um processo em que os estudantes adentram em uma nova cultura a partir dos conhecimentos sobre ciências e o modo como estão inseridos na sociedade, sendo mais críticos e conscientes de suas ações (SASSERON, 2008). Nesse sentido, a ideia de alfabetizar cientificamente na visão dessa autora assemelha-se à de Lorenzetti e Delizoicov 
(2001) para quem o indivíduo compreende os significados das ciências, ampliando, desse modo, seus conhecimentos científicos.

Os autores se referem à cultura científica, e para isso faz-se necessário que a AC seja considerada uma alternativa que torna possível a formação de cidadãos críticos e capazes de tomar decisões, superando assim algumas das dificuldades do Ensino de Ciências. Além de contribuir para o desenvolvimento do espírito crítico, a AC possibilita ao estudante compreender e avaliar impactos que diferentes informações sobre ciência podem gerar em contextos sociais e escolares (OLDONI; LIMA, 2017). Neste sentido, Sasseron e Carvalho (2011) defendem que o desenvolvimento da Alfabetização Científica tem se tornado cada vez mais urgente para todos e discutem a relevância do debate dessas ideias ao longo dos anos, constatando que a AC possui maior atenção quando desenvolvida em contextos de educação formal.

Além disso, outros autores têm discutido sobre reformas educativas a fim de desenvolver habilidades e competências que objetivem a AC. Costa e Lorenzetti (2020), por exemplo, ressaltam a importância da promoção de uma educação reflexiva dos estudantes conscientes na tomada de decisões, mediante atuação de um corpo docente envolvido nas discussões sobre formação de cidadãos críticos em meio a cenários da sociedade, de modo que os sujeitos sejam capazes de compreender a ciência, suas mudanças, bem como suas diversas aplicações na vida prática e cotidiana.

No intuito de superar o ensino tradicional/conteudista, pautado apenas na transmissão de informações aos alunos e nos aspectos conceituais, professores e pesquisadores vêm discutindo diferentes práticas pedagógicas indispensáveis para o bom desenvolvimento da aprendizagem de conhecimentos científicos, reafirmando a importância de algumas abordagens e estratégias de ensino e aprendizagem com vista a contribuir para o desenvolvimento de um pensamento mais crítico nos estudantes (ZÔMPERO; LABURÚ, 2012; SUART; MARCONDES, 2018). É nesse âmbito que os pressupostos da AC surgem como uma necessidade da educação em ciências, visando à formação cidadã consciente e crítica em relação ao mundo, ou seja, a AC planeja um ensino que dê possibilidade aos alunos de conhecerem uma nova cultura, novas maneiras de ver o mundo e seus acontecimentos, podendo modificá-los através de suas ações e habilidades associadas ao fazer científico (SASSERON; CARVALHO, 2011).

Para Oldoni e Lima (2017), apesar de a AC ser um dos pressupostos do Ensino de Ciências, há muitos desafios que dificultam tal abordagem, como por exemplo os 
métodos pedagógicos em que os professores os apresentam de maneira dogmática e sem qualquer reflexão crítica, o que reforça ainda mais a lacuna na formação inicial e continuada dos professores. Para que as práticas e os métodos pedagógicos sejam potencializadores no processo de ensino e aprendizagem, reconhecemos como necessário que os cursos de formação de professores de Ciências ofereçam condições para que os licenciandos aprendam e discutam, além dos conteúdos das disciplinas específicas, novas metodologias de ensino e aprendizagem, tendo a possibilidade de refletir criticamente acerca do ensinar e aprender Ciências (SUART; MARCONDES, 2018; OLIVEIRA; OBARA, 2018).

Muitos cursos de licenciatura baseiam-se em concepções tradicionais e técnicas de ensino que separam aspectos teóricos da prática. Além disso, diversos conteúdos específicos que estão dispostos nos currículos desses cursos pouco se relacionam com os conhecimentos necessários para a prática docente. As experiências vivenciadas por licenciandos nesses cursos levam os futuros professores a reproduzirem, tanto em seus discursos e planejamentos como em suas futuras aulas, estratégias que pouco contribuem para a aprendizagem dos alunos (SUART; MARCONDES, 2018).

De acordo com Cachapuz, Gil-Perez e Pessoa (2011), a AC tornou-se uma exigência essencial para o desenvolvimento da sociedade. Os autores a reconhecem como essencial, uma vez que a AC frequentemente aparece nos debates acerca das metodologias do Ensino de Ciências e das necessidades de reformas educativas. Tais necessidades de reforma são indispensáveis para que os professores tenham conhecimentos sobre maneiras de ensinar Ciências, aproximando-se da forma como o conhecimento científico é construído, enriquecendo a visão dos cidadãos sobre a natureza da Ciência, visto que muitas vezes os professores a ensinam de forma inadequada (OLDONI; LIMA, 2017; CONCEIÇÃO; OLIVEIRA; FIREMAN, 2020).

Segundo Andrade e Abílio (2018), e diante do que vem sendo explanado, entende-se que a AC pode proporcionar aos indivíduos uma participação ativa também sobre a Ciência e as implicações dela na sociedade; nesse sentido, é importante que os professores busquem atingir tais objetivos, proporcionando um fazer científico que começa na formação do indivíduo desde o ensino fundamental, até o ensino superior. Chassot (2010) também enfatiza a necessidade em se preocupar significativamente com os objetivos que visem a $\mathrm{AC}$ na educação básica e também a ampliação de propostas de AC no ensino superior. 
Nesse sentido, podemos citar os três eixos da AC (SASSERON, CARVALHO, 2011, p. 75-76): "compreensão básica de termos, conhecimentos e conceitos científicos fundamentais; compreensão da natureza das Ciências e dos fatores éticos e políticos que circundam sua prática; entendimento das relações existentes entre ciência, tecnologia, sociedade e meio ambiente". Segundo essas autoras:

[...] esses três eixos são capazes de fornecer bases suficientes e necessárias de serem consideradas no momento da elaboração e planejamento de aulas e propostas de aulas que visam à Alfabetização Científica.

[...] as propostas didáticas que surgirem respeitando esses três eixos devem ser capazes de promover o início da Alfabetização Científica, pois terão criado oportunidades para trabalhar problemas envolvendo a sociedade e $\mathrm{o}$ ambiente, discutindo, concomitantemente, os fenômenos do mundo natural associados a construção do entendimento sobre esses fenômenos e os empreendimentos gerados a partir de tal conhecimento (SASSERON; CARVALHO, $2011 \mathrm{p}$. 75-76).

$\mathrm{O}$ que as autoras apresentam e discutem reforça o que é imprescindível para $o$ advento da formação dos professores, no sentido de que os conteúdos científicos sejam planejados e trabalhados de forma contextualizada em sala de aula. Ao professor é dada a tarefa de valorizar suas aulas de Ciências, oferecendo aos seus alunos diferentes modos de perceber o mundo em que vivem, problematizando os conceitos, conduzindo os estudantes de forma significativa a imergir em uma cultura que os permita assumir, além da compreensão da AC, novas noções e conhecimentos científicos.

Além de uma concepção consolidada a respeito da AC a fim de promovê-la, acreditamos que outras características possam ser aliadas à prática pedagógica $\mathrm{e}$ ao desempenho de professores da educação básica, visando alfabetizar cientificamente os estudantes. Concordamos com Marin (2011) ao destacar a importância da Didática nesse contexto e ampliar a discussão sobre essa área de conhecimento, sinalizando sua importância, entre tantas facetas, para a formação de professores, pois segundo o autor:

Ela é fundamental nessa finalidade, componente central do currículo dos cursos de formação de professores. É o momento de se disseminar o conhecimento existente para auxiliar os novos professores a se prepararem para o desempenho de sua função nas salas de aula, pois nessa circunstância - nos cursos de formação - aprendem-se, por meio da Didática, vários princípios, procedimentos e atitudes para serem considerados bons professores, que saibam ensinar e que seus alunos aprendam (MARIN, 2011, p. 18-19). 
Reconhecemos então que são vários os aspectos que norteiam o desempenho dos professores nos mais variados âmbitos em que atuam. A maior parte desses aspectos é fomentada durante a formação inicial, e embora a disseminação de conhecimentos essenciais que vão desde os conteúdos até as práticas de como ensiná-los não seja contemplada em sua totalidade nessa etapa, vemos na formação continuada um espaço fundamental para a construção do diálogo entre a teoria e a prática educativa, de acordo com o que Marin (2011) chama de "ensinar para que os alunos aprendam" (p. 19).

Nessa perspectiva, Pimenta (2012) expõe algumas reflexões a partir de experiências do desenvolvimento do ensino de Didática nos cursos de licenciatura e das pesquisas realizadas sobre a formação inicial e continuada. A autora afirma utilizar as pesquisas em Didática a serviço da reflexão dos alunos e da constituição de suas identidades docentes. Além disso, problematiza as pesquisas diante da realidade escolar com a intenção de promover nos alunos atitudes investigativas.

Outro aspecto indispensável no contexto institucional dos diferentes estágios de formação de professores é o desenvolvimento de uma prática visando torná-los profissionais reflexivos, abrindo espaço para essa reflexão na ação e para a ação (SCHÖN, 1992). O autor destaca o termo praticums reflexivos e elenca algumas dificuldades para a introdução de um praticum reflexivo, como a epistemologia da universidade e o currículo profissional formativo. Segundo o autor:

Primeiro ensinam-se os princípios científicos relevantes, depois a aplicação desses princípios e, por último, tem-se um praticum cujo objetivo é aplicar à prática cotidiana os princípios da ciência aplicada. Mas, de fato, se o praticum quiser ter alguma utilidade, envolverá sempre outros conhecimentos diferentes do saber escolar. Os alunos-mestres têm geralmente consciência deste desfasamento, mas os programas de formação ajudam-nos muito pouco a lidar com essas discrepâncias (SCHÖN, 1992, p. 91).

Diante de tais apontamentos, entendemos que durante a formação docente, a ideia de reflexão seja uma atividade ligada à aprendizagem profissional, permitindo ao professor estar continuamente em um processo de aprendizagem acerca da sua prática, visando pensar e repensar o trabalho docente. Além disso, pautando-se nas concepções de Tardif e Moscoso (2018) acerca das limitações da ideia de um profissional reflexivo: "os professores devem fazer de suas práticas profissionais uma matéria de reflexão, para lhes dar sentido" (p. 404) e, portanto, uma prática 
que contemple aspectos que ultrapassem uma consciência privada e exclusa de interação com o social.

\section{Procedimentos Metodológicos}

A pesquisa bibliográfica foi realizada no período de 2014 a 2019. Embora haja uma quantidade significativa de estudos em períodos anteriores, esse recorte de tempo foi selecionado em função de verificar nos trabalhos mais recentes as discussões tecidas sobre AC na formação de professores.

A pesquisa foi efetivada em 7 (sete) dos principais periódicos científicos na área de Educação em Ciências avaliados entre A1 e A2 pela Coordenação de Aperfeiçoamento de Pessoal de Nível Superior (CAPES). Além disso, para a escolha dos periódicos, consideramos também a representatividade que possuem as revistas na comunidade acadêmica. As seguintes revistas foram selecionadas para análise: Alexandria: Revista de Educação em Ciência e Tecnologia; Ciência \& Educação; Investigações em Ensino de Ciências; Revista Ensaio Pesquisa em Educação em Ciências; Revista Brasileira de Pesquisa em Educação de Ciências. Revista de Ensino de Ciências e Matemática; Revista Actio Scientiarum. Education.

Compreendemos que as revistas selecionadas sejam suficientes para o objetivo do estudo, e certamente não teríamos categorias diferentes caso a busca fosse ampliada para outras revistas. Além disso, no intuito de complementar a análise em outros documentos, analisamos também os trabalhos publicados nos Anais do Encontro Nacional de Pesquisa em Educação em Ciências (ENPEC), promovido pela Associação Brasileira de Pesquisa em Educação em Ciências (ABRAPEC) dos últimos 7 (sete) anos. Justifica-se a escolha em analisar trabalhos deste evento por caracterizar-se como o principal evento nacional em pesquisas na área de Educação em Ciências com a finalidade de divulgar os trabalhos relacionados a essa área de conhecimento.

Inicialmente, no sistema de busca das revistas, procuramos pelo termo Alfabetização Científica e Formação de Professores nos títulos. Após selecionar todos os artigos para uma pré-análise, utilizamos o sistema do Adobe Acrobat Reader DC, buscando pelas expressões: Formação de Professores, Alfabetização Científica, Cultura Científica, Formação Inicial, Formação Continuada, Enculturação Científica, Indicadores de Alfabetização Científica, Letramento Científico, para assim constatar em quais contextos a AC estava sendo mencionada. No sistema de busca dos 
Anais dos ENPEC, selecionamos a área de conhecimento Formação de Professores e buscamos nos resumos e palavras-chave dos trabalhos pelas mesmas expressões.

Após selecionar os trabalhos, optamos em definir que a análise seria desenvolvida mediante a perspectiva de André (2013). Segundo a autora, quanto a pesquisas de abordagens qualitativas, o rigor metodológico não é estabelecido pela atribuição de um nome, mas pela descrição clara do percurso realizado para atingir os objetivos propostos, justificando cada escolha e se preocupando com o rigor científico do trabalho.

A princípio, elencamos alguns focos temáticos a fim de compreender o contexto geral no qual os trabalhos se inserem: 1) ano de publicação; 2) instituição de ensino, estado e região; 3) contexto educacional; 4) principal objetivo nos artigos identificados. Ao realizar a pré-análise, dividimos o estudo em três aspectos essenciais, que trabalharemos como categorias de análise: a) Sentidos/significados atribuídos pelos professores em formação à $\mathrm{AC}$; b) Abordagens e estratégias utilizadas nos processos formativos que divulguem procedimentos de ensino para a promoção da AC; c) Reflexão e delineamento acerca da prática pedagógica objetivando a AC.

\section{Resultados e Discussão}

Na primeira etapa desta investigação, identificamos um total de 125 artigos, sendo que 21 foram localizados nos periódicos e 104 nos anais do ENPEC. Em uma segunda etapa, os trabalhos selecionados foram criteriosamente analisados quanto ao foco desta investigação: AC no contexto da Formação de Professores. Após esse processo de análise, o número final de artigos incluídos neste estudo foi de 23 trabalhos, sendo 6 das revistas selecionadas e 17 trabalhos do ENPEC. Destacamos que esse número final de artigos não se limita à quantidade de trabalhos relacionados a essa temática, os critérios de exclusão dos artigos foram pesquisas realizadas no Ensino Fundamental, Ensino Médio, trabalhos de revisão e ensaio teórico.

O Quadro 1 apresenta a distribuição dos artigos de acordo com o recorte temporal selecionado para esta investigação, considerando para análise os trabalhos com foco na AC no contexto da Formação de Professores para a análise. 


\begin{tabular}{|c|c|c|c|c|c|c|c|c|}
\hline $\begin{array}{c}\text { Fonte dos } \\
\text { dados/ Ano } \\
\text { de } \\
\text { publicação }\end{array}$ & 2013 & 2014 & 2015 & 2016 & 2017 & 2018 & 2019 & $\begin{array}{l}\text { Total de } \\
\text { trabalhos }\end{array}$ \\
\hline Alexandria & & 0 & 0 & 0 & 0 & 0 & 0 & 0 \\
\hline $\begin{array}{l}\text { Ciência e } \\
\text { Educação }\end{array}$ & & 0 & & 0 & 0 & 0 & 0 & 0 \\
\hline $\begin{array}{l}\text { Revista de } \\
\text { Ensino de } \\
\text { Ciências e } \\
\text { Matemática }\end{array}$ & & 0 & 0 & 0 & 0 & 1 & 0 & 1 \\
\hline Ensaio & & 0 & 1 & 0 & 0 & 1 & 0 & 2 \\
\hline $\begin{array}{l}\text { Investiga- } \\
\text { ções em } \\
\text { Ensino de } \\
\text { Ciências }\end{array}$ & & 0 & 2 & 0 & 0 & 0 & 0 & 2 \\
\hline $\begin{array}{l}\text { Revista } \\
\text { Brasileira } \\
\text { de Pesquisa } \\
\text { em Edu- } \\
\text { cação em } \\
\text { Ciências }\end{array}$ & & 0 & 0 & 0 & 0 & 1 & 0 & 1 \\
\hline $\begin{array}{l}\text { Acta Scien- } \\
\text { tiarum Edu- } \\
\text { cation }\end{array}$ & & 0 & 0 & 0 & so & 0 & 0 & 0 \\
\hline ENPEC & 4 & $-n / a$ & 7 & $-n / a$ & 4 & $-n / a$ & 2 & 17 \\
\hline TOTAL & & & & & & & & 23 \\
\hline
\end{tabular}

Fonte: dados da pesquisa (2019). n/a: Não se aplica, pois não houve edição do ENPEC.

É importante destacar que o ENPEC é um evento bianual; mesmo assim, a quantidade de trabalhos publicados em suas atas é mais expressiva do que nas revistas, evidenciando o papel democrático e abrangente do evento em questão. A pouca quantidade de artigos nas revistas nos leva a supor que, embora a temática da AC e sua promoção em sala de aula venha sendo discutida há muito tempo, ainda não há um número expressivo de pesquisas que investigam a formação do professor com vistas à instrumentalização teórica e prática para a promoção da AC.

Os dados relativos ao desenvolvimento das pesquisas, em termos de instituição de ensino, estado e região, estão apresentados no Gráfico 1. Percebemos em termos quantitativos as regiões nas quais os trabalhos são mais eminentes: 
Gráfico 1 - Distribuição dos artigos localizados por regiões brasileiras

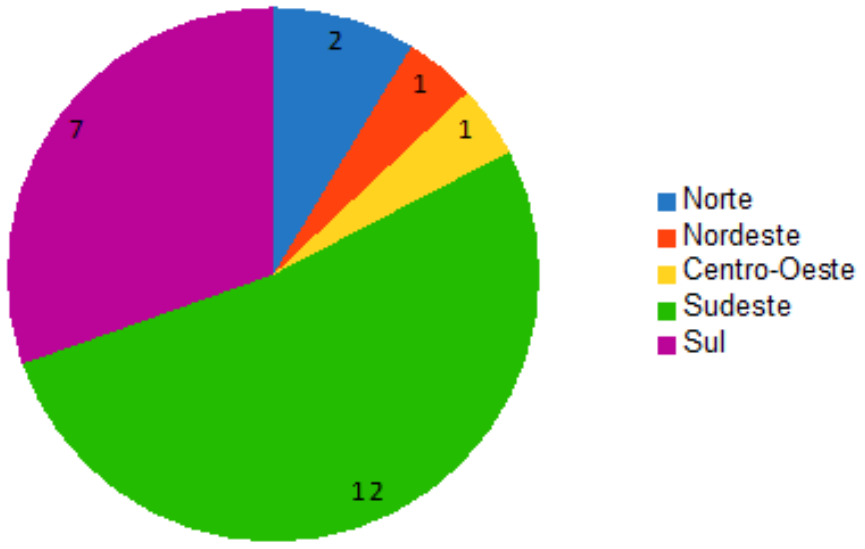

Fonte: dados da pesquisa (2019).

Percebemos maior expressividade nas regiões Sudeste (12) e Sul (7), ou seja, mais da metade dos trabalhos analisados concentram-se nos estados de São Paulo, Rio de Janeiro, Minas Gerais, Espírito Santo, Paraná e Rio Grande do Sul. Enquanto dois trabalhos são da região Norte, ambos do Pará, um trabalho é na região Centro-Oeste e apenas um na região Nordeste, sendo este da Paraíba. Outro dado que merece destaque é o fato de todos os trabalhos, sem exceção, serem oriundos de Universidades Federais e Estaduais, o que indica que talvez as instituições públicas sejam as que mais investem e promovem a formação de professores.

Os trabalhos analisados compreendem diferentes contextos educacionais. Há pesquisas que direcionam o seu foco para a formação inicial, a saber, 12 trabalhos. As demais pesquisas concentram-se nos cursos de formação continuada, além das pesquisas realizadas com professores durante a sua própria prática pedagógica. Os artigos estão distribuídos nas áreas de Biologia, Física, Química e Pedagogia.

Quanto aos objetivos principais das pesquisas, há estudos cuja preocupação está centrada nas necessidades formativas e aprendizagem docente tendo em vista a preparação para atuar nos processos de ensino e aprendizagem nos anos iniciais e finais do Ensino Fundamental e no Ensino Médio (PIRES; MALACARNE, 2018; PIZARRO; LOPES, 2013) e que avaliam a importância de trabalhar a AC nos cursos de formação inicial (ROCHA et al., 2019; NUNES; MESQUITA, 2019) seja 
por meio de projetos de ensino ou de abordagens sobre temas que tenham relação direta com o seu cotidiano.

Alguns trabalhos se voltam para a análise de atividades de investigação desenvolvidas nos processos de formação (inicial e continuada) e outros para a implementação delas, objetivando discutir estratégias didáticas e formas de avaliação das propostas que promovam a alfabetização científica no Ensino Fundamental e no Ensino Médio, analisando desde os eixos e indicadores de AC (SOUZA; BASTOS, 2013; VERSUTI-STOQUE; FREIRE; MOTOKANE, 2013; MIRANDA; SUART; MARCONDES, 2015; SILVA et al., 2015; SILVA; SILVA, 2015; LOPES; JESUS; GARCIA, 2017; MAIA; DITZEL, 2017; PEREIRA; SOUZA, 2017; SUART; MARCONDES, 2018) até propostas de atividades de caráter investigativo e níveis cognitivos presentes nas propostas de ensino, possibilitando a AC aos estudantes dos cursos de formação (IWTA; LUPETI, 2015; SUART et al., 2015 ; SANTOS; PESSOA, 2017).

Há também trabalhos que analisam as percepções dos docentes quanto ao que se discute sobre $\mathrm{AC}$ em busca de estabelecer relação entre as práticas de $\mathrm{AC}$ e 0 espaço escolar, seja no Ensino Fundamental ou no Ensino Médio (CATANOZI, 2015; ANDRADE; ABÍLIO, 2018; TAUCEDA et al., 2015; LIMA; GARCIA, 2015; CAZAROTTI; MOTOKANE, 2013). Entre estes, um artigo se propõe a compreender as noções de classificação do processo da AC: prático, cívico, cultural e econômica ou profissional (MILARÉ; FRANCISCO, 2015).

Todos os trabalhos preocupam-se, em alguma medida, com a relação estabelecida entre o professor e a sala de aula, tanto no contexto da formação inicial como nos cursos de formação continuada, incluindo professores novatos ou experientes. Os trabalhos voltados para formação inicial direcionam suas análises ao desenvolvimento de propostas e/ou abordagens didáticas que ao serem desenvolvidas promovam a AC. Os que investigam a percepção dos professores durante a sua prática preocupam-se com a identidade assumida por eles sobre a temática em questão.

Quanto aos principais resultados e conclusões apontados nos trabalhos, a primeira constatação observada é a necessidade de ampliação de uma carga horária que permita aos professores, ao vivenciarem práticas voltadas para a AC ainda na graduação, ter um maior aprofundamento dos saberes relacionados a essa temática. Desse modo, há maior possibilidade de os professores potencializarem as práticas desenvolvidas em sala de aula. 


\section{Sentidos/significados atribuídos pelos professores à AC}

Nos baseamos na percepção de Chassot (2003) para compreender os sentidos nos quais os professores têm pensado na sua prática pedagógica. $\mathrm{O}$ autor afirma que "ser alfabetizado cientificamente é saber ler a linguagem em que está escrita a natureza. É um analfabeto científico aquele incapaz de uma leitura do universo" (2003, p. 91).

Para Sasseron (2015), ensinar Ciências na perspectiva de envolver questões que irão além do seu contexto implica dar atenção aos seus produtos e processos, bem como construir um entendimento sobre os fenômenos do mundo e o impacto deles em nossas vidas. A autora reforça a ideia de que apenas reconhecer termos e conceitos da Ciência não leva a uma compreensão de mundo, dos fenômenos naturais e impactos dela na nossa vida, pois estes podem se modificar, e na perspectiva da AC, o conhecimento torna-se contínuo.

Tomando por base os artigos analisados, discutiremos então se esses sentidos atribuídos pelos professores sobre a definição da AC estão em consonância com o que estudos apontam como crucial para ser alfabetizado cientificamente. Certamente, há pesquisas em que se nota a preocupação dos autores quanto à percepção dos professores sobre AC; nelas, os autores evidenciam a intenção de investigar a partir de atividades e/ou propostas didáticas desenvolvidas, tendo como foco principal a AC. Outros estudos apresentam a ideia de que para tais propostas se efetivarem, é necessário haver pelo menos a presença de alguns níveis de $\mathrm{AC}$ - conceitual, nominal e funcional - por parte dos licenciandos, como nos trechos a seguir:

Quanto ao nível de alfabetização científica (AC) [...] verifica-se nas propostas 1 e 2 a presença dos níveis de $\mathrm{AC}$ nominal, o qual requer que o estudante somente reconheça um conceito, sem necessariamente compreendê-lo [...] e AC funcional, onde o aluno é capaz de responder utilizando a forma conceitual correta. (SUART et al., 2015, p. 205)

Ao comparar a segunda proposta em relação à primeira, verificamos um progresso quanto ao nível de alfabetização científica. Esta evolui de alfabetização científica nominal, proposta 1 , para alfabetização científica funcional, proposta 2 , onde, nesta última, os alunos podem descrever corretamente um conceito, porém, podem apresentar compreensão limitada sobre o mesmo. (SUART et al., 2015, p. 205)

Há ainda artigos que se inserem no contexto da formação continuada que buscam, por meio de situações-problema, levar os professores a vivenciarem a ressig- 
nificação de suas concepções quanto ao que compreendem sobre AC. Podemos ver a seguir trechos de alguns trabalhos:

[...] ressaltamos que, além de conhecer as concepções docentes sobre os diversos elementos que compõem a AC, é preciso que sejam realizados estudos que acompanhem essas práticas e identifiquem as fragilidades e potencialidades encontradas, relacionando-as com as concepções e com as necessidades formativas dos professores. (ANDRADE; ABÍLIO, 2018, p. 449)

[...] o professor explicita conhecimentos que podem não estarem totalmente corretos do ponto de vista daqueles aprendidos nas IES, mas são aqueles que o professor compreende como adequados para responder aquelas situações. Ele ressignifica então os conceitos aprendidos na academia. (TAUCEDA et al., 2015, p. 5)

Para outros professores, a AC significa a compreensão dos processos por trás da Ciência, seu funcionamento, e até mesmo associam a AC à linguagem científica. No sentido de vivenciar a Alfabetização Científica, há professores que afirmam, no que diz respeito às vivências, que a $\mathrm{AC}$ seria motivar nos alunos o gosto pela Ciência, contribuindo na aprendizagem e oportunizando condições efetivas para que os alunos assumam uma postura crítica e reflexiva frente as situações que os cercam. Nessa perspectiva, destacamos os trechos a seguir:

[...] os professores afirmaram que vivenciar a $\mathrm{AC}$ é despertar nos alunos o gosto pelo 'fazer ciência', tornando isso 'atraente', 'estimulante' e 'apaixonante' e que buscam colocar isso em suas práticas [...] trabalhar a AC é uma maneira de melhorar o aprendizado dos alunos, de suprir diversas dificuldades que permeiam o processo de ensino-aprendizagem. (ANDRADE; ABÍLIO, 2018, p. 444)

Para cada professor há um significado bastante diferente que vai desde 'metodologia científica' até 'metodologia para alfabetizar' até 'popularização do conhecimento científico'. (CAZAROTTI; MOTOKANE, 2013, p. 6)

A formação da cidadania é também mencionada pelos professores como objetivo do ensino de Ciências por pelo menos três professores. Outros professores relacionam o ensino e Ciências à possibilidade do aluno ter uma visão de mundo que pode ser associada a sua própria realidade. (SOUZA; BASTOS, 2013, p. 5)

[...] parte do objetivo da alfabetização científica também se refere a proporcionar condições de os alunos fazerem uso, por si mesmos, de todo o aporte possibilitado por essa concepção do Ensino de Ciências, para facilitar o dia-a-dia e a vida em sociedade. (PEREIRA; SOUZA, 2017 , p. 5) 
Nessa perspectiva, Sasseron (2015) afirma que a AC, assim como na Ciência, está sempre em um processo de construção, pois à medida que as situações mudam, novos conhecimentos são construídos e podem impactar nosso entendimento, decisões e posicionamentos mediante as relações entre as Ciências, a sociedade e as diversas áreas do conhecimento, sendo essas perspectivas associadas à Alfabetização Científica.

Em contrapartida, identificamos trabalhos que, ao analisar a percepção docente do processo de AC no Ensino Fundamental, trazem na sua discussão aspectos vistos como necessários no professor quanto aos seus objetivos de ensino de modo que, além de professor, seja também um pesquisador, e possua uma visão multidimensional da Alfabetização Científica. Entretanto a visão apresentada pelos docentes é de que essa não seria a prioridade das instituições de ensino, como observado no trecho a seguir:

Em depoimento, professores exibiram preocupação e entendimento quanto à importância e à necessidade de se incluírem práticas pedagógicas para a alfabetização científica, mas têm como percepção que esta não seja o foco primordial das instituições de ensino. (CATANOZI, 2015, p. 7)

Outro trabalho que busca, por meio das percepções dos licenciandos, produzir materiais que possuam foco no ensino objetivando a $\mathrm{AC}$, leva em consideração o que Sasseron (2015) aponta sobre nossas decisões e posicionamentos mediante as relações entre as Ciências, sociedade e a preocupação com o meio ambiente. Como podemos observar a seguir:

[...] a compreensão do impacto da ciência e da tecnologia nos indivíduos e na sociedade. A HQ número 1 problematiza a questão do descarte indevido de lixo no meio ambiente. A linguagem simples, com pouco texto e bem ilustrada, se torna adequada ao público-alvo desta HQ, que são as crianças. Além disso, é uma HQ educativa no sentido de mostrar às crianças preocupações com o meio ambiente e o desenvolvimento sustentável. (IWTA; LUPETTI, 2015, p. 6)

Questões como estas se inserem no terceiro eixo estruturante da AC, apontado por Sasseron (2008, p. 335) como "entendimento das relações existentes entre ciência, tecnologia, sociedade e meio ambiente". Diferente do que percebemos no trabalho de Silva e Silva (2015):

No que se refere à alfabetização científica, pudemos perceber uma preocupação maior com a compreensão básica da a compreensão básica de termos, conhecimentos e conceitos científicos e pouca ou nenhuma preocupação com a concepção da natureza das Ciências e com entendimento das relações existentes entre CTSA. (SILVA; SILVA, 2015, p. 7) 
O Quadro 2 traz uma síntese dos resultados encontrados nesta categoria, separando-os em formação inicial e continuada, a fim de esclarecer um pouco mais o que vem se destacando nos trabalhos.

Quadro 2 - Sentidos e significados atribuídos à AC - síntese

\begin{tabular}{|c|c|}
\hline Elementos destacados na formação inicial & Estudo(s) que discute(m) a temática \\
\hline $\begin{array}{l}\text { Concepção dos significados da Alfabetização } \\
\text { Científica a partir de propostas didáticas de- } \\
\text { senvolvidas pelos licenciandos, havendo, ao } \\
\text { menos, a presença de alguns níveis de AC - } \\
\text { conceitual, nominal ou funcional. }\end{array}$ & Suart et al. (2015) \\
\hline $\begin{array}{l}\text { Propostas didáticas desenvolvidas pelos licen- } \\
\text { ciandos, com enfoque na AC e preocupação } \\
\text { com a relação Ciência, Tecnologia e Sociedade. }\end{array}$ & Iwta e Lupetti (2015) \\
\hline $\begin{array}{l}\text { Ressignificação das concepções de AC a partir } \\
\text { das vivências, com visões de mundo sobre Ci- } \\
\text { ência associadas à realidade do próprio sujeito. }\end{array}$ & Pereira e Souza (2017) \\
\hline $\begin{array}{l}\text { Visão da AC como sendo basicamente a com- } \\
\text { preensão de termos, conhecimentos e conceitos } \\
\text { científicos. }\end{array}$ & Silva e Silva (2015) \\
\hline $\begin{array}{l}\text { Elementos destacados na formação } \\
\text { continuada }\end{array}$ & Estudo(s) que discutem $(\mathrm{m})$ a temática \\
\hline $\begin{array}{l}\text { Inserção de situações problema no contexto da } \\
\text { formação continuada para provocar os professo- } \\
\text { res a ressignificarem seus conhecimentos sobre } \\
\text { AC. }\end{array}$ & $\begin{array}{l}\text { Andrade e Abílio (2018) } \\
\text { Cazarotti e Motokane (2013) } \\
\text { Souza e Bastos (2013) }\end{array}$ \\
\hline $\begin{array}{l}\text { Ressignificação das concepções de AC como } \\
\text { processo contínuo, a partir dos conceitos apren- } \\
\text { didos na formação inicial. }\end{array}$ & Tauceda et al. (2015); Andrade e Abílio (2018) \\
\hline $\begin{array}{l}\text { Inserção de práticas pedagógicas visando maior } \\
\text { aprofundamento sobre AC desde a formação } \\
\text { inicial. }\end{array}$ & Catanozi (2015) \\
\hline
\end{tabular}

Fonte: dados da pesquisa (2019).

Os autores chamam atenção para o fato de os professores se limitarem a aspectos conceituais da Alfabetização Científica, dessa maneira pouco se aproximam de compreensões sobre aspectos da natureza da Ciência e em como a AC contribui no entendimento de outras questões importantes do cotidiano. Assim, salientamos como indispensável inserir na formação de professores discussões e maior aprofundamento quanto aos significados atribuídos à $\mathrm{AC}$. 
É válido salientar que ainda há uma concepção equivocada da sociedade quanto à própria palavra "Ciência", o que limita a sua compreensão enquanto presente no dia a dia frente à tomada de decisões conscientes. De acordo com Lorenzetti e Delizoicov (2001), embora a Alfabetização Científica possa contribuir fortemente na formação de futuros cientistas, não é esse o seu principal objetivo. Visa que seus significados sejam compreendidos e aplicados para o entendimento do mundo. A escola tem papel fundamental de colocar os estudantes em contato com essas informações, o que constitui um desafio aos docentes promover de forma contextualizada os significados dos conceitos que lhes são apresentados.

\section{Abordagens e estratégias utilizadas nos processos formativos de professores para a AC}

A partir do que já exploramos acerca dos sentidos que os professores atribuem à $\mathrm{AC}$, percebemos que nesse processo, além das concepções, é necessário que eles tenham durante a sua formação experiências com as diversas metodologias, abordagens e estratégias possíveis que possam ser utilizadas, visando uma formação docente que contemple aspectos importantes para a prática pedagógica. Nesse sentido, percebemos que esse objetivo esteve presente em 7 trabalhos analisados, o que corresponde a aproximadamente $30,4 \%$ dos artigos incluídos neste estudo.

Nas propostas que potencializam os processos de ensino e aprendizagem na perspectiva da AC, enquadram-se os trabalhos que buscam, por meio de projetos de pesquisa e extensão, uma maior interação entre as disciplinas nas quais os professores lecionam e/ou irão lecionar com o ambiente escolar e o cotidiano.

[...] os projetos interdisciplinares, projetos de pesquisas e projetos de extensão, podem possibilitar ao professor momentos de compartilhamento enriquecedores de aprendizagem do conteúdo a ser ensinado, desde que organizados em grupos de estudo envolvendo toda a escola e não de forma isolada. (PIRES; MALACARNE, 2018, p. 64)

[...] em nosso contexto de educadores-pesquisadores, trazer para o centro do palco uma dinâmica capaz de fomentar espaços-tempos que possibilitem um ato educativo crítico-reflexivo, no que concerne aos ambientes costeiros e suas implicações para a vida humana [...] quanto à construção da aprendizagem de conceitos científicos que envolvam conteúdos transdisciplinares [...] em face das variadas possibilidades de interação do estudante como protagonista na construção do seu próprio conhecimento e em situações reais. (SILVA et al., 2015, p. 4) 
O projeto de ensino é uma via alternativa para os alunos participarem plenamente da vida universitária como demonstrou um dos alunos: [...] no início do curso tivemos contato com a dinâmica do rigor técnico, a orientação, o desenvolvimento e apresentação de seminários, a escrita e a busca por literatura especializada, que será comum na vida acadêmica. (ROCHA et al., 2019, p. 5)

É importante destacar a preocupação em colocar o educando no processo de aprendizagem, desenvolvendo pensamento crítico para a sua tomada de decisões frente a questões relacionadas ao homem e ao meio ambiente. Chassot (2003) ressalta como sendo inerente ao sujeito alfabetizado cientificamente a prática pedagógica que exija do aluno a relação entre saberes científicos e a utilização em seu cotidiano, o que estimula novas leituras de mundo. Além disso, esta perspectiva está de acordo com as habilidades discutidas por Sasseron (2011, p. 67), entre elas "conheça as fontes válidas de informação científica e tecnológica e recorra a elas quando diante de situações de tomada de decisões".

Com relação às abordagens de ensino que possuem por objetivo a AC, alguns trabalhos explanaram atividades de investigação em que os professores puderam refletir sobre situações-problema; atividades experimentais e de investigação; problematização da sua própria prática. Desse modo, sendo orientados ao planejamento e desenvolvimento delas, possibilitando, a partir da sua prática, que os estudantes participem de forma ativa na interação com o professor para a construção do seu conhecimento. Alguns trabalhos evidenciaram esse aspecto:

O desenvolvimento dos projetos foi realizado por meio dos momentos metodológicos do ato educativo - planejamento, ação, observação e reflexão. Para a realização das aulas de Física (ação) seguimos os momentos pedagógicos, as reflexões foram feitas por meio da leitura e discussão dos registros, para então ter subsídios para a elaboração do próximo planejamento. (MAIA; DITZEL, 2017, p. 4)

A sequência de aulas proposta e ministrada pelo licenciando $\mathrm{R}$ se aproximou de uma atividade por investigação. Uma justificativa para isso está no fato de ele ter reconhecido a importância da questão problema em atividades dessa natureza desde o início do PRO e sustentado o desenvolvimento desse elemento pedagógico durante toda sua ação em sala de aula. (SUART; MARCONDES, 2018, p. 24).

Essa metodologia de $\mathrm{PRO}^{1}$ busca investigar durante a formação inicial do professor o que ele "fala" e "faz", levando-o a uma reflexão acerca da sua prática discursiva e do seu desenvolvimento profissional (ALVES; LIMA; MARCONDES,

1 Processo de Reflexão Orientada. 
2012). Do ponto de vista pedagógico, podemos inferir que as atividades desenvolvidas a partir de um problema se mostram eficientes frente à importância de um aprendizado que irá além de conceitos, objetivam o desenvolvimento da AC. Essas ideias coadunam com os achados de Zômpero e Laburú (2011) na medida em que esses autores evidenciaram que elas não se limitam à aprendizagem de conceitos disciplinares, mas configuram como um ensino capaz de oferecer aos estudantes oportunidades reais de participarem ativamente do processo de construção do seu conhecimento.

Além disso, outra evidência nos trabalhos refere-se aos processos formativos dos professores de pedagogia em formação inicial, como apontado por Pires e Malacarne (2018), sendo importante investir em projetos interdisciplinares de pesquisa e extensão. Essas ideias corroboram com os achados de Pizarro e Lopes (2013) que também evidenciavam essa necessidade em seus estudos. Segundo os autores: "pode-se oferecer indícios dos saberes docentes que fundamentam a prática das professoras, possíveis necessidades formativas para o Ensino de Ciências na formação continuada de professores." (p. 7).

Ao analisar o trabalho de Nunes e Mesquita (2019), percebemos a necessidade da AC nos mais variados âmbitos da sociedade, embora alguns cursos (nesse caso de química) ofereçam disciplinas específicas sobre radioatividade, elas não são obrigatórias. "Considerando que os professores formados por essas instituições irão atuar na educação básica e, provavelmente, ministrarão a seus alunos o conteúdo de radioatividade, uma vez que este está presente nos livros didáticos do Ensino Médio" (p. 6), o que os autores trazem como tema no trabalho são as dificuldades em contribuir na perspectiva da Alfabetização Científica dos estudantes em relação ao tema da radioatividade na educação básica, uma vez que o professor não tem uma informação sólida o bastante que leve os estudantes a ressignificarem esses conceitos científicos.

Alguns trabalhos destacam as potencialidades das atividades de investigação e/ou propostas didáticas orientadas ainda na formação inicial, visando permitir aos professores que elaborem, apliquem e avaliem tais propostas, buscando sempre relacionar aspectos práticos e teóricos na sua prática que permitam aos alunos vivenciar etapas do fazer científico e assim evidenciar aspectos significativos da AC. As propostas de ensino para os professores nos trabalhos atentam à contextualização, considerando aspectos sociais, culturais, gerando discussão entre os professores 
sobre o conhecimento científico articulado à Tecnologia, Sociedade e Ambiente (MIRANDA; SUART; MARCONDES, 2015; SILVA; SILVA, 2015).

Ainda com relação ao desenvolvimento de propostas didáticas pelos professores, os trabalhos de Suart e Marcondes (2018), Santos e Pessoa (2017) e Iwta e Lupetti (2015) constatam que trabalhar as dificuldades dos licenciandos quanto a tais propostas que promovam a AC nos alunos os oportuniza reelaborar suas concepções acerca das atividades que o professor irá propor a fim de promover a AC durante suas atividades.

Quando os trabalhos tratam de investigações em sala de aula, como desenvolvimento das propostas didáticas pelo professor, surgem discussões sobre as perspectivas de ensino e aprendizagem que os docentes apresentam, suas dificuldades em promover condições adequadas de interação entre o professor-aluno que viabilizem 0 desempenho dos alunos nas atividades que correspondem aos eixos e indicadores da AC. Resultados também apontam que tais estratégias utilizadas pelos professores podem promover a $\mathrm{AC}$, dando possibilidade de ir além dos conteúdos estipulados no currículo, consequentemente desenvolvendo conhecimentos práticos, contextualizados, necessários para viver em sociedade com uma visão de mundo mais ampliada, no sentido de conduzir os alunos a uma postura crítica sobre Ciência e Tecnologia (CHASSOT, 2003).

Zômpero, Gonçalves e Laburú (2017) se baseiam em alguns referenciais na afirmativa de que os estudantes podem desenvolver competências que conduzam a conhecimentos científicos, aprendam a discutir e refletir, posicionando-se criticamente sobre as implicações desses avanços para a sociedade mediante a AC, indo além de conteúdos conceituais e procedimentais. E se é importante que isso seja proporcionado aos alunos, cabe aos professores, no contexto em que estiverem se formando, compreender os pressupostos da AC, conhecer as Ciências a fim de que possam facilitar suas vivências. É nesse sentido que alguns trabalhos trazem a ideia de que os professores se preocupem quanto ao entendimento da importância e necessidade de incluírem em sua prática pedagógica atividades para a AC.

Embora a maioria dos trabalhos ressalte essa demanda, Catanozi (2015) afirma que

[...] as práticas docentes mostraram-se significativamente convencionais, fundamentadas especialmente na exposição, dialógica ou não, e nos registros em lousa, sendo uma contradição entre os anseios, as cobranças e as ações efetivas. Nesse aspecto, deve-se considerar a impor- 
tância negativa da necessidade pela demonstração de resultados mais satisfatórios para os indicadores de desempenho educacional, que podem deturpar os objetivos mais importantes do Ensino de Ciências. (CATANOZI, 2015, p. 7)

Essa realidade pode ser explicada a partir dos resultados de alguns trabalhos (SOUZA; BASTOS, 2013) que ao investigarem como os professores lidam com a AC na Educação Básica perceberam, a partir de suas respostas, que muitos justificam trabalhar conteúdos de Ciências nos anos iniciais por uma determinação curricular, mostrando assim que não há outra razão para ensinar Ciências, senão pela obrigatoriedade do currículo. Andrade e Abílio (2018), em uma pesquisa mais recente, constataram que os professores não apresentaram aprofundamento conceitual sobre a AC, corroborando com a citação anterior, pois se restringem apenas ao caráter formal na disciplina de Ciências, e considerando que alguns professores possuíam formação relativamente recente, seus resultados apontam que

[...] as práticas relatadas pelos professores do presente estudo se direcionam para a dimensão funcional da ciência, apresentando um reducionismo sobre o que seria $\mathrm{AC}$, fator que estimula visões deformadas a respeito da própria ciência, uma vez que a preocupação excessiva com a questão do método exclui outras dimensões importantes para a construção dessa área, como as dimensões histórica, filosófica e sociológica. (ANDRADE; ABÍLIO, 2018, p. 447)

Quanto à articulação entre formação de professores e AC, os artigos apontam que há algumas apropriações que merecem atenção. De acordo com Lopes, Jesus e Garcia (2017), por exemplo, na formação continuada, além do conhecimento da matéria a ser ensinada, deve ser feito o questionamento das concepções dos professores sobre ensino e aprendizagem de Ciências. Além disso, é necessário preparar as atividades de maneira que os estudantes construam seus conhecimentos e saber orientar e avaliar esses alunos por meio de ações e abordagens visando a AC.

Ainda sobre essa articulação, alguns trabalhos buscaram situar-se no lugar de quem alfabetiza cientificamente, na tentativa de pensar em possibilidades de levar os alunos a se tornarem autores da sua descoberta nesse processo de AC. Pereira e Souza (2017) discutem que inicialmente o professor deve reconhecer as suas capacidades e limitações, o que de certa forma corrobora com Lopes, Jesus e Garcia (2017) que pontuam sobre a importância de a atividade docente ser ancorada na própria consciência enquanto educador com responsabilidade social e cultural, configurando situações de reflexões críticas acerca do mundo em que vivemos, estabelecendo, dessa forma, relações entre a $\mathrm{AC}$ e as perspectivas que ela oferece. 
No Quadro 3, destacam-se alguns elementos apresentados nos artigos quanto às propostas de metodologias, abordagens e estratégias que contemplam aspectos da AC na Formação Docente.

Quadro 3 - Abordagens e estratégias visando a AC - síntese

\begin{tabular}{|c|c|}
\hline Elementos destacados na formação inicial & Estudo(s) que discute(m) a temática \\
\hline $\begin{array}{l}\text { Propostas pautadas em projetos de pesquisa e ex- } \\
\text { tensão sob enfoque da AC, articulando sala de aula e } \\
\text { cotidiano dos estudantes para os quais irão lecionar. }\end{array}$ & $\begin{array}{l}\text { Pires e Malacarne (2018); Rocha et al. } \\
\text { (2019) }\end{array}$ \\
\hline $\begin{array}{l}\text { Aprofundamento sobre propostas com enfoque em } \\
\text { situações-problema; atividades experimentais e de } \\
\text { investigação. }\end{array}$ & $\begin{array}{l}\text { Miranda, Suart, Marcondes (2015); Silva e } \\
\text { Silva (2015); Suart e Marcondes (2018) }\end{array}$ \\
\hline $\begin{array}{l}\text { Propostas didáticas dos professores em atividades } \\
\text { de problematização visando a AC, de modo que } \\
\text { trabalhem suas próprias limitações, visando maior } \\
\text { compreensão dos significados da Alfabetização Cien- } \\
\text { tífica. }\end{array}$ & $\begin{array}{l}\text { Maia e Ditzel (2017); Iwta e Lupetti (2015); } \\
\text { Santos e Pessoa (2017) }\end{array}$ \\
\hline Elementos destacados na formação continuada & Estudo(s) que discute(m) a temática \\
\hline $\begin{array}{l}\text { Propostas pautadas em projetos de pesquisa e ex- } \\
\text { tensão sob enfoque da AC, articulando sala de aula e } \\
\text { cotidiano dos estudantes para quem lecionam. }\end{array}$ & Silva et al. (2015) \\
\hline $\begin{array}{l}\text { Necessidade do desenvolvimento mais frequente de } \\
\text { projetos interdisciplinares, de pesquisa e extensão, } \\
\text { visando alfabetizar cientificamente. }\end{array}$ & Pizarro e Lopes (2013) \\
\hline $\begin{array}{l}\text { Abordagens ancoradas no trabalho de reflexão sobre } \\
\text { a própria prática, visando articulação teórico-prática } \\
\text { da AC. }\end{array}$ & Lopes, Jesus e Garcia (2017) \\
\hline
\end{tabular}

Fonte: dados da pesquisa (2019).

Reflexão e delineamento acerca da prática pedagógica objetivando a AC

Dada a importância de vários aspectos indispensáveis para a aprendizagem profissional, Tardif e Moscoso (2018) destacam a reflexão como sendo uma outra fonte importante quando aliada diretamente à ação. Os autores afirmam ser coerente o que se espera de um profissional que avalia suas ações e busca melhorar sua prática pedagógica, no entanto, esta deve ser realizada em conformidade com a mudança esperada de acordo com determinado elemento em diferentes situações.

Com base nisso, foram identificados alguns trabalhos que dispõem dessa preocupação na formação de professores, tais como a busca pela ruptura no modelo tradicional de ensino, pois durante a formação inicial pode ocorrer ausência de uma 
reflexão crítica que considere uma mudança na atitude dos licenciandos quanto a sua didática, suas ideias e concepções acerca de como ensinar, como observado a seguir:

Reforça-se, nesse sentido, a importância da formação inicial docente proporcionar reflexões epistemológicas, uma vez que essa perspectiva pode contribuir para a formação do futuro professor, de forma que desenvolvam uma postura de criticidade e reflexão sobre as suas ações didático-pedagógicas. (PIRES; MALACARNE, 2018, p. 73)

A prática reflexiva proporciona aos professores em formação continuada e inicial questionar suas práticas de ensino, permitindo a estes oportunidades de rever e analisar acontecimentos e experiências, contribuindo para o seu desenvolvimento profissional. (MIRANDA; SUART; MARCONDES, 2015, p. 559)

Andrade e Abílio (2018) também destacam em seu trabalho a necessidade de os currículos das licenciaturas empenharem-se com a formação, visando uma prática pedagógica crítica e reflexiva. É importante notar que a discussão acerca da reflexão é abrangente, destacada como indispensável para ações pedagógicas, contudo, ressaltamos que para a finalidade do ensino que vise promover a AC, além de refletir sobre a ação, é importante que os professores compreendam que tais ações precisam acontecer. Tardif e Moscoso (2018) questionam o que o professor reflete sobre ou durante sua prática, seja quanto às dificuldades na gestão das aulas, conteúdos, ou as políticas de trabalho, entre diversos elementos e que não cabem em uma simples reflexão, hora na ação ou depois dela.

Quanto à reflexão e delineamento acerca da $\mathrm{AC}$, alguns dos trabalhos tratam da elaboração de propostas voltadas com essa finalidade, como forma de garantir aos professores conhecimentos que venham proporcionar aos seus alunos uma compreensão de mundo consciente (PIRES; MALACARNE, 2018). Podemos observar a seguir alguns trechos em que a finalidade da reflexão é a AC:

[...] é importante salientar que o processo de reflexão sobre a elaboração de sua unidade, ocorrido previamente à regência em sala, ao longo dos encontros individuais e/ou em grupo no PRO, foi essencial para a licenciada elaborar aulas com características investigativas e para a promoção da AC e desenvolvê-las com maior consciência sobre elas e sobre suas ações. (MIRANDA; SUART; MARCONDES, 2015, p. 580)

[...] despertar uma reflexão a respeito dos cursos de licenciatura em Ciências Biológicas e sobre a necessidade de buscar o desenvolvimento da Alfabetização Científica no contexto da formação inicial de professores. (LIMA; GARCIA, 2015, p. 7) 
Os trechos acima fundamentam-se nas concepções de Oldoni e Lima (2017) quanto ao processo de reflexão dos professores sobre suas próprias práticas que levem em conta o delineamento de uma formação de cidadãos para transformações sociais e saberes necessários para serem alfabetizados cientificamente.

Em três dos trabalhos analisados, foi possível perceber a prática fomentada por propostas de atividades que puderam ser vistas como uma maneira de avaliar a ação docente mediante a implementação e reflexão pelos próprios professores. Vejamos a seguir algumas dessas atividades:

O modelo apresentado ajudou a professora avaliar que as ações docentes adotadas priorizaram a reprodução dos conteúdos científicos propostos na SD, restringindo a autonomia dos alunos e o diálogo em sala de aula. Dessa forma, o procedimento se configurou como uma estratégia efetiva para estimular a postura de um profissional reflexivo e crítico de sua realidade de atuação. (VERSUTI-STOQUE; FREIRE; MOTOKANE, 2013, p. 7)

[...] os futuros professores, ao elaborar propostas de sequências didáticas, abordam temas de Zoologia a partir de várias estratégias didáticas, sendo as SDs um importante instrumento de planejamento do ensino e reflexão da prática pedagógica. (SILVA; SILVA, 2015, p. 7)

Os mesmos trabalhos trouxeram ainda um aspecto importante quanto aos indicadores da AC, destacados por Sasseron (2008) como competências próprias da ciência e do fazer científico e se tratam de habilidades ligadas à construção do conhecimento a partir da resolução de problemas vinculados às ciências. Nos trabalhos a seguir, percebe-se que os professores compreendem a importância destes indicadores estarem em processo em sala de aula, evidenciando papel ativo dos estudantes na construção do conhecimento.

[...] a professora, a partir da reflexão mediada pela interpretação funcional das interações discursivas, planejará e aplicará uma nova sequência didática visando à melhoria da qualidade dos indicadores de alfabetização científica a serem obtidos. (VERSUTI-STOQUE; FREIRE; MOTOKANE, 2013, p. 7)

A nossa proposta de inserir os indicadores de alfabetização científica neste diálogo teve como objetivo refletir em conjunto com as professoras se seria possível reconhecer e elencar indicadores de aprendizagem (no caso, de alfabetização científica) [...] Na tentativa de oferecer a oportunidade para refletir sobre quais suportes poderiam auxiliar o professor na busca por reconhecer indicadores de alfabetização científica, [...]. (PIZARRO; LOPES, 2013, p. 7)

O Quadro 4 apresenta de forma sintetizada algumas ideias e concepções sobre reflexão na prática pedagógica com foco na Alfabetização Científica. 
Quadro 4 - Reflexão e delineamento acerca da prática pedagógica objetivando a AC - síntese

\begin{tabular}{|l|l|}
\hline Elementos destacados na formação inicial & Estudo(s) que discute(m) a temática \\
\hline $\begin{array}{l}\text { Reflexões epistemológicas visando desenvolver } \\
\text { criticidade, contribuindo no processo de forma- } \\
\text { ção docente. }\end{array}$ & $\begin{array}{l}\text { Pires, Malacarne (2018); Miranda, Suart e } \\
\text { Marcondes (2015) }\end{array}$ \\
\hline $\begin{array}{l}\text { Processo de Reflexão Orientada (PRO) sob en- } \\
\text { foque da AC promovida por meio de abordagens } \\
\text { de investigação. }\end{array}$ & Miranda, Suart e Marcondes (2015) \\
\hline $\begin{array}{l}\text { Reflexão seguida da implementação de Sequên- } \\
\text { cia Didática visando a AC sobre sua importância } \\
\text { em sala de aula. }\end{array}$ & Silva e Silva (2015) \\
\hline Elementos destacados na formação continuada & Estudo(s) que discute(m) a temática \\
\hline $\begin{array}{l}\text { Maior destaque nos currículos das licenciaturas } \\
\text { quanto ao empenho com a formação docente, } \\
\text { visando uma prática pedagógica crítica e refle- } \\
\text { xiva. }\end{array}$ & Andrade e Abílio (2018); Lima e Garcia (2015) \\
\hline $\begin{array}{l}\text { Reflexão na prática docente sobre a importância } \\
\text { da AC na sala de aula articulada ao cotidiano } \\
\text { dos estudantes. }\end{array}$ & Versuti-Stoque, Freire e Motokane (2013); \\
\hline
\end{tabular}

Fonte: dados da pesquisa (2019).

A reflexão na formação dos professores é repleta de significados, contudo, nos ancoramos na ideia de reflexão partindo da crítica, assim o professor pode se aprofundar na mudança da prática pedagógica para sua ação, conforme elencado por Tardif e Moscoso (2018), enriquecendo a visão de profissional reflexivo por meio de sua conexão com a tradição da reflexão crítica.

A ideia de reflexão na qual nos pautamos e consideramos pertinente na Formação Docente converge aos objetivos da Alfabetização Científica, uma vez que a AC perpassa pelas atribuições de caráter crítico e argumentativo. Desse modo, é necessário fomentar a formação dos educadores com propostas que ultrapassem ideias abstratas, integrando propostas teórico-práticas na relação AC e Formação Docente.

\section{Considerações Finais}

A presente pesquisa analisa quais os principais aspectos da Alfabetização Científica estão presentes durante a formação inicial e continuada de professores, com o intuito de auxiliá-los durante a sua prática em sala de aula, a partir da construção de propostas de ensino que tenham por objetivo promover o desenvolvimento da AC nos estudantes. 
A partir das discussões na categoria Sentidos/significados atribuídos pelos professores em formação à $\mathrm{AC}$, evidencia-se que, embora possuam alguma ideia sobre AC, há pouco aprofundamento quanto ao que se objetiva para a formação cidadã em termos de diálogo, reflexão, criticidade, entre outros aspectos. Entretanto, verificou-se que os trabalhos no contexto educacional da formação continuada revelaram certa preocupação quanto a oportunizar aos professores vivenciarem e ressignificarem sua compreensão acerca da AC.

Destaca-se que as instituições de ensino superior investem na formação docente qualificada, objetivando a promoção de propostas efetivas da AC, visto que alguns professores não a enxergam como essencial para a sua formação cidadã. Esse aspecto foi possível ser identificado na concepção de alguns professores nos trabalhos que investigaram o contexto da formação inicial, nos quais os professores apontam que sua compreensão sobre AC decorre de processos que envolvem a Ciência, como esta funciona e também da linguagem científica.

Identificamos, a partir da discussão na categoria Abordagens e estratégias utilizadas nos processos formativos, inquietações quanto a propiciar aos professores o contato com diferenciadas abordagens, estratégias e metodologias que possibilitem aos estudantes em sala de aula atingir determinados níveis de AC. As atividades de investigação mostraram-se como uma das mais utilizadas quando se deseja motivar os estudantes à criticidade na tomada de decisões e posicionamentos frente à Ciência, Tecnologia, Sociedade e Meio Ambiente. Quanto à preocupação e necessidade de reflexão discutida na categoria Reflexão e delineamento acerca da prática pedagógica objetivando a AC, constatamos que as pesquisas evidenciam a relevância de reflexões sobre os conceitos que permeiam a $\mathrm{AC}$ articulados às propostas, abordagens e metodologias que objetivem a natureza de seus argumentos. Notou-se que, no contexto da formação de professores, situações-problema que levem a uma reflexão sobre a 'prática docente' podem contribuir na evolução de concepções epistemológicas e pedagógicas dos professores. Reiteramos ainda a ideia de reflexão na qual nos baseamos frente aos resultados encontrados, da qual espera-se que venha acompanhada da mudança da postura do professor mediante sua prática pedagógica.

Sasseron (2015) ressalta que a AC é um processo contínuo e por isso precisa estar em construção em diversos âmbitos, incluindo novos conhecimentos decorrentes de novas situações evidenciadas pelas relações entre a Ciência e a Sociedade. Para tanto, os professores precisam imergir em práticas e atividades problematizadoras, uma 
vez que a formação docente para a educação básica, como já discutida anteriormente, deve proporcionar aos estudantes a capacidade de relacionar os temas estudados com a sua realidade. Nesse sentido, destacamos como fundamental considerar e explorar aspectos da AC no âmbito da formação de professores, visando torná-los ainda mais críticos e reflexivos na sua prática pedagógica, podendo promover a AC no contexto da educação básica.

Ao considerar os diversos aspectos da AC durante a formação inicial e/ou continuada, os professores poderão proporcionar aos seus educandos compreensões além dos conteúdos disciplinares e favorecer o entendimento a respeito de si mesmos como parte do meio ambiente, de maneira participativa em sociedade e assim promover mudanças significativas na realidade em que vivem. Evidenciamos ainda como fundamental a mudança na prática pedagógica, visto que os trabalhos majoritariamente fundamentam e se ancoram coerentes ao que se espera de cidadãos alfabetizados cientificamente. Ou seja, a ideia de AC motivada no âmbito da formação de professores propicia também a articulação com a cidadania por meio da conexão entre conhecimento científico e sua relação com o cotidiano.

Destacamos como relevante atentar-se às características da $\mathrm{AC}$ nos cursos de formação em todos os contextos, utilizando metodologias, abordagens e estratégias que auxiliem os professores na sua prática em sala de aula. Assim indagamos: como requerer dos futuros professores a articulação de aspectos teóricos da AC, quanto à sua compreensão e abordagens que promovam sua reflexão prática, se não a valorizarmos ainda durante a sua formação inicial?

Acreditamos que a evidência de trabalhos nas demais regiões possa ser incitada e que as instituições formadoras valorizem propostas como esta, bem como se perpetue cada vez mais a evidência das pesquisas nas universidades públicas, que, como identificamos, são as maiores investidoras em pesquisas na formação docente e nas demais áreas de investigação, a fim de que os futuros professores possam vivenciar os processos da AC. Como elenca Leite e Rodrigues (2018), é importante refletir sobre a estrutura dos cursos de formação, considerando aspectos sociocientíficos a serem abordados nas disciplinas da área de ensino que contemplem formação integral do licenciando. Como já mencionamos, há poucos trabalhos voltados a essa temática no contexto educacional de formação docente. Diante disso, é indispensável pautar-se em ações que analisem não apenas proposições conceituais, mas também mudan- 
ças de atitudes por parte dos professores mediante os processos que viabilizem as características da promoção da AC na educação básica.

\section{Scientific Literacy Inherent in Teacher Education: What does research say about the perspectives for Science Teaching}

\section{Abstract}

Several researches have investigated the teaching and learning of sciences focusing on Scientific Literacy (CA) aiming at a formation of citizens that goes beyond conceptual learning. However, few of them investigate the training of teachers to act in the classroom regarding their approach to CA processes. Thus, the aim of the present study was to analyze, with a view to teacher education, the teaching strategies used to promote CA and how teaching approaches have approached discussions about scientific practice. For this, a survey was conducted in the main journals of the Science Teaching area and the annals of the National Meeting of Research in Science Education (ENPEC) from 2014 to 2019. The categories of analysis were: meanings/ meanings attributed by teachers to CA; approaches and strategies used in CA-focused training processes; and reflection on the pedagogical practice aiming at CA. We identified a few works in the initial and continuing formative context of teachers. The results highlight that there is still little depth regarding the discussions of aspects that contemplate the objectives of CA. The idea of reflecting on its characteristics is encouraged in the works, however, the reflection is still based on a more general idea, without discussing the change to the practice of teachers. Still, some works highlight, as the main means of promoting $\mathrm{CA}$, investigative activities, since they direct teachers to criticality, reflections, among other skills necessary for a person to be scientifically literate. We then emphasize the importance of incorporating into teacher training actions that enable a change in attitudes towards their classroom practice in basic education.

Keywords: Scientific Literacy. Science teaching. Teacher training. Initial and Continuing Formation

\section{Referências}

ALVES, Fabrício; LIMA, Viviane; MARCONDES, Maria Eunice Ribeiro. O ensino experimental como ferramenta metodológica em um processo de formação continuada na perspectiva da reflexão orientada. In: Encontro Nacional de Ensino de Química. Anais XVI ENEQ / X EDUQUI. Salvador, BA, 2012.

ANDRADE, Maria José Dias de; ABÍLIO, Francisco José Pegado. Alfabetização Científica no Ensino de Biologia: Uma Leitura Fenomenológica de Concepções Docentes. Rev. Bras. Pesquisa em Educação em Ciências, Belo Horizonte, v. 18, n. 2, p. 429-453, ago. 2018. 
ANDRÉ, Marli. O que é um estudo de caso qualitativo em educação. Revista da FAEEBA Educação e Contemporaneidade, Salvador, v. 22, n. 40, p. 95-103, jul./dez. 2013.

BRITO, Liliane Oliveira de; FIREMAN, Elton Casado. O Ensino de Ciências por investigação: uma estratégia pedagógica para promoção da alfabetização científica nos primeiros anos do ensino fundamental. Revista Ensaio, Belo Horizonte. v. 17, n. 3, p. 555-583, set-dez. 2016.

CACHAPUZ, Antonio; GIL-PEREZ, Daniel; PESSOA, Ana Maria. A necessária Renovação do Ensino das Ciências. 3 ed. São Paulo: Cortez, 2011.

CARVALHO, Anna Maria Pessoa de. O Ensino de Ciências e a proposição de sequências de ensino investigativas. In: Ensino de Ciências por Investigação: condições para implementação em sala de aula. São Paulo: CENGAGE Learning, 2013.

CARVALHO, Anna Maria Pessoa de; GIL-PÉREZ, Daniel. Formação de professores de ciências: tendências e inovações. 10 ed. São Paulo: Cortez, 2011.

CATANOZI, Gerson. Análise de estratégias pedagógicas para a alfabetização científica no ensino Fundamental I à luz da percepção docente. In: Encontro Nacional de Pesquisa em Educação em Ciências. 10. Atas. Águas de Lindóia, SP, p. 1-8, 2015.

CAZAROTTI, Ana Claudia; MOTOKANE, Marcelo Tadeu. Concepção de professores sobre Biodiversidade e Alfabetização Científica. In: Encontro Nacional de Pesquisa em Educação em Ciências. 9. Atas. Águas de Lindóia, SP, p. 1-8, 2013.

CHASSOT, Attico. Alfabetização Científica: questões e desafios para a educação. 3. ed. Ijuí: Unijuí, 2003.

CHASSOT, Attico. Alfabetização Científica: questões e desafios para a educação. 4. ed. Ijuí: Unijuí, 2010.

CHASSOT, Attico. Alfabetização Científica: questões e desafios para a educação. 8. ed. Ijuí: Unijuí, 2018.

CONCEIÇÃO, Alexandre Rodrigues; OLIVEIRA, Rosemeire da Silva; FIREMAN, Elton Casado. Ensino de Ciências por Investigação: Uma Estratégia Didática para Auxiliar a Prática dos Professores dos Anos Iniciais do Ensino Fundamental. Revista Brasileira de Ensino de Ciências e Matemática, Passo Fundo, v. 3, n. 1, p. 76 - 98, jan./jun. 2020.

COSTA, Ellen Moreira; LORENZETTI, Leonir. A promoção da alfabetização científica nos anos finais do ensino fundamental por meio de uma sequência didática sobre crustáceos. Revista Brasileira de Ensino de Ciências e Matemática, Passo Fundo, v. 3, n. 1, p. 11 - 47, jan./jun. 2020.

IWTA, Adriana Yumi; LUPETTI, Karina Omuro. A Alfabetização científica em química por meio das histórias em quadrinhos. In: Encontro Nacional de Pesquisa em Educação em Ciências. 10. Atas. Águas de Lindóia, SP, p. 1 - 8, 2015.

LEITE, Rosana Franzen; RODRIGUES, Maria Aparecida. Aspectos sociocientíficos e a questão ambiental: uma dimensão da alfabetização científica na formação de professores de química. Revista de Ensino de Ciências e Matemática, Cruzeiro do Sul, v. 9, n. 3, p. 38-53, 2018.

LIMA, Amanda Muliterno Domingues Lourenço; GARCIA, Rosane Nunes. A Alfabetização Científica de estudantes de licenciatura em Ciências Biológicas: um estudo de caso no contexto da formação inicial de professores. In: Encontro Nacional de Pesquisa em Educação em Ciências. 10. Atas. Águas de Lindóia, SP, p. 1-8, 2015. 
LOPES, Werner Zacarias; JESUS, Rhenan Ferraz; GARCIA, Rosane Nunes. AC e CTS na produção científica dos últimos cinco anos no Brasil: necessidade de discussões sobre Formação Continuada. In: Encontro Nacional de Pesquisa em Educação em Ciências. 11. Atas. Florianópolis, SC, p. 1-10, 2017.

LORENZETTI, Leonir; DELIZOICOV, Demétrio. Alfabetização Científica no contexto das séries iniciais. Ensaio - Pesquisa em Educação em Ciências, Belo Horizonte, v. 3, n. 1, p. 45-61, jan-jun. 2001.

MAIA, Dayane Rejane Andrade; DITZEL, Dair Gabriel. As possibilidades e limites da Alfabetização Científica e Tecnológica no ensino de Física no curso Técnico Integrado em Alimentos. In: Encontro Nacional de Pesquisa em Educação em Ciências. 11. Atas. Florianópolis, SC, p. 1 - 11, 2017.

MARIN, Alda Junqueira. Didática geral. In: Caderno de Formação: formação de professores didática geral. UNIVERSIDADE ESTADUAL PAULISTA. São Paulo: Cultura Acadêmica, v. 9, p. 16-32, 2011.

MILARÉ, Tathiane; FRANCISCO, Kelly. “Química, pra que te quero?”: argumentos de licenciandos na perspectiva da Alfabetização Científica. In: Encontro Nacional de Pesquisa em Educação

em Ciências. 10. Atas. Águas de Lindóia, SP, p. 1 - 8, 2015.

MIRANDA, Mayara de Souza; SUART, Rita de Cássia; MARCONDES, Maria Eunice Ribeiro. Promovendo alfabetização científica por meio do ensino investigativo no ensino médio de química: contribuições para formação inicial docente. Revista Ensaio, Belo Horizonte, v. 17, n. 3, p. 555-583, set-dez. 2015.

NUNES, Luclécia Dias; MESQUITA, Nyuara Araújo da Silva. Análise da temática radioatividade nos PPC de Licenciatura em Química do estado de Goiás. In: Encontro Nacional de Pesquisa em Educação em Ciências. 12. Atas. Natal, RN, p. 1- 7, 2019.

OLDONI, Josiane Fátima Weimer Baierle; LIMA, Barbara Grace Tobaldini de. A compreensão dos professores sobre a Alfabetização Científica: perspectivas e realidade para o Ensino de Ciências. ACTIO, Curitiba, v. 2, n. 1, p. 41-59, jan./jul. 2017.

OLIVEIRA, André Luis de; OBARA, Ana Tiyomi. O Ensino de Ciências por investigação: vivências e práticas reflexivas de professores em formação inicial e continuada. Investigações em Ensino de Ciências, Rio Grande do Sul, v. 23, n. 2, ago. p. 65 - 87, 2018.

PEREIRA, Patricia Darci; SOUZA, Lúcia Helena Pralon de. Formação do Professor: reconhecendo-se na Alfabetização Científica. In: Encontro Nacional de Pesquisa em Educação em Ciências. 11. Atas. Florianópolis, SC, p. 1 - 9, 2017.

PIMENTA, Selma Garrido. Saberes pedagógicos e atividade docente. 8. ed. São Paulo: Cortez, 2012.

PIRES, Elocir Aparecida Corrêa; MALACARNE, Vilma. Formação inicial de professores no curso de pedagogia para o Ensino de Ciências: representações dos sujeitos envolvidos. Investigações em Ensino de Ciências, Rio Grande do Sul, v. 23, n. 1, p. 56 - 78, abr. 2018.

PIZARRO, Mariana Vaitiekunas; LOPES, Jair Junior. Necessidades formativas dos professores dos anos iniciais do ensino fundamental para o Ensino de Ciências no contexto dos sistemas de avaliação em larga escala. In: Encontro Nacional de Pesquisa em Educação em Ciências. 9. Atas. Águas de Lindóia, SP, 1 - 8, 2013. 
ROCHA, Marla Piumbini; SILVA, Adriana Lourenço da; RODRIGUEZ, Rita de Cássia Morem Cossio; LÜDTKE, Raquel. Alfabetização Científica como via para um currículo emancipatório. In: Encontro Nacional de Pesquisa em Educação em Ciências. 12. Atas. Natal, RN, p. $1-9,2019$.

SANTOS, Thais Priscila Bahia dos; PESSOA, Wilton Rabelo. O processo de ferrugem como tema de investigação na formação de professores para os anos iniciais do Ensino Fundamental. In: Encontro Nacional de Pesquisa em Educação em Ciências. 11. Atas. Florianópolis, SC, $1-8,2017$.

SASSERON, Lúcia Helena. Alfabetização científica no ensino fundamental: estrutura e indicadores deste processo em sala de aula. 2008. Tese (Doutorado em Educação) - Faculdade de Educação, Universidade de São Paulo, São Paulo, 2008.

SASSERON, Lúcia Helena; CARVALHO, Anna Maria Pessoa de. Alfabetização Científica: uma revisão bibliográfica. Investigações em Ensino de Ciências, Rio Grande do Sul, v. 16, n. 1, p. 59-77, 2011.

SASSERON, Lúcia Helena. A alfabetização científica, ensino por investigação e argumentação das relações entre ciências da natureza e escola. Revista ensaio, Belo Horizonte, v. 17, n. especial, p. $49-67$, nov. 2015.

SASSERON, Lúcia Helena; DUSCHL, Richard. Ensino de Ciências e as Práticas Epistêmicas: o papel do professor e o engajamento dos estudantes. Investigações em Ensino de Ciências, Rio Grande do Sul, v. 21, n. 2, p. 52, 2016.

SEDANO, Luciana; CARVALHO, Anna Maria Pessoa de. Ensino de Ciências por investigação: oportunidades de interação social e sua importância para a construção da autonomia moral. Alexandria, Santa Catarina, v. 10, p. 199-220, 2017.

SILVA, Gabriel de Moura; SILVA, Rosana Ferreira Louro. Problematizando o ensino de Zoologia na educação básica a partir de sequências didáticas produzidas por licenciandos. In: Encontro Nacional de Pesquisa em Educação em Ciências. 10. Atas. Águas de Lindóia, SP, 1 - 8, 2015.

SILVA, Marcelo Scabelo da; CAMPOS, Carlos Roberto Pires; FERRAZ, Vasty Veruska Rodrigues; CONDE, Juliana; LOPES, Fernando Pinto. Aula de campo e alfabetização científica em ambientes costeiros: atividades colaborativas nas falésias do sul capixaba. In: Encontro Nacional de Pesquisa em Educação em Ciências. 10. Atas. Águas de Lindóia, SP, 1 - 8, 2015.

SCHÖN, Donald. Formar professores como profissionais reflexivos. In: NÓVOA, Antônio. Os professores e sua formação. Lisboa: Dom Quixote, 1992.

SOUZA, Maria de Jesus; BASTOS, Sandra Nazaré Dias. Ensino de Ciências e alfabetização: casamento (im) possível? In: Encontro Nacional de Pesquisa em Educação em Ciências. 9. Atas. Águas de Lindóia, SP, p. 1 - 8, 2013.

SUART, Rita de Cássia; ABRAS, Camila Marra; MACULAN, Débora; PEDROSO, Jackeline Rafaela; ROSA, Lívia Maria Ribeiro; MIRANDA, Mayana; BERNARDO, Rodrigo Antônio; MARCONDES, Maria Eunice Ribeiro. Uma análise do desenvolvimento de sequências de aulas por licenciandas de química ao longo de um processo de reflexão orientada. Investigações em Ensino de Ciências, Rio Grande do Sul, v. 20, n. 2, p. 186 - 208, 2015. 
SUART, Rita de Cássia; MARCONDES, Maria Eunice Ribeiro. O processo de reflexão orientada na formação inicial de um licenciando de química visando o ensino por investigação e a promoção da alfabetização científica. Revista Ensaio, Belo Horizonte, v. 20, 2018.

TARDIF, Maurice; MOSCOSO, Javier Nunez. A noção de "profissional reflexivo" na educação: atualidade, usos e limites. Cadernos de pesquisa, São Paulo, v. 48, n. 168, p. 388-411, abr/jun. 2018.

TAUCEDA, Karen Cavalcanti; DEL PINO, José Cláudio; NUNES, Leticia Magdaleno; WITT, Neila. A Alfabetização Científica em Situações-Problema: um Conceito Norteador para uma Metodologia Investigativa na Formação Continuada dos Professores de Química. In: Encontro Nacional de Pesquisa em Educação em Ciências. 10. Atas. Águas de Lindóia, SP, 2015, p. 1 - 8.

VERSUTI-STOQUE, Fabiana Maris; FREIRE, Caio Castro; MOTOKANE, Marcelo Tadeu. A análise de interações discursivas na formação de professores de ciências. In: Encontro Nacional de Pesquisa em Educação em Ciências. 9. Atas. Águas de Lindóia, SP, p. 1 - 8, 2013.

ZÔMPERO, Andreia Freitas; LABURÚ, Carlos Eduardo. Atividades investigativas no ensino de ciências: aspectos históricos e diferentes abordagens. Revista Ensaio, Belo Horizonte, v. 13, n. 3, p. $67-80,2011$.

ZÔMPERO, Andreia Freitas; LABURÚ, Carlos Eduardo. Implementação de atividades investigativas na disciplina de ciências em escola pública: uma experiência didática. Investigações em Ensino de Ciências, Rio Grande do Sul, v. 17, n. 3, p. 675-684, 2012.

ZÔMPERO, Andreia Freitas; GONÇALVES, Carlos Eduardo de Souza; LABURÚ, Carlos Eduardo. Atividades de investigação na disciplina de Ciências e desenvolvimento de habilidades cognitivas relacionadas a funções executivas. Ciência e Educação, Bauru, v. 23, n. 2, p. 419 - 436, 2017. 